\title{
Instrumentos para captação e análise acústica dos sinais de ausculta cervical na prática clínica fonoaudiológica: uma revisão integrativa de literatura
}

\author{
Instruments for acoustic capture and analysis of cervical auscultation
} signals in speech-language pathology clinic practice: an integrative

\author{
literature review
}

Valdani Dias (1), Geovana de Paula Bolzan² (D)

\begin{abstract}
RESUMO
Objetivo: Descrever os instrumentos utilizados para captação e análise acústica dos sinais de ausculta cervical e identificar aqueles com maior potencial para aplicação na clínica fonoaudiológica. Estratégia de pesquisa: Trata-se de uma revisão integrativa de literatura. As buscas foram realizadas nas bases de dados MEDLINE/PubMed, Scopus e Web of Science, a partir da combinação de termos de relevância e operadores booleanos, durante o mês de novembro de 2020. Critérios de seleção: Artigos científicos publicados nos idiomas português, espanhol ou inglês, nos últimos cinco anos (2016-2020) e que apresentassem estudo da ausculta cervical. Resultados: Foram encontrados 98 artigos. Após a aplicação dos critérios de seleção, 26 artigos foram selecionados para esta revisão. Para captação dos sinais de ausculta cervical, o microfone foi o instrumento mais utilizado, seguido pela técnica de ausculta cervical de alta resolução, que combina sinais acústicos e vibratórios registrados por um microfone e um acelerômetro, respectivamente. Softwares e/ou algoritmos foram selecionados para análise acústica dos sinais, de acordo com o objetivo de cada estudo. Conclusão: $\mathrm{O}$ método de ausculta cervical de alta resolução e a análise acústica por meio de algoritmos de aprendizado de máquina apresentaram grande potencial para utilização na prática clínica fonoaudiológica para avaliação e monitoramento da deglutição.
\end{abstract}

Palavras-chave: Deglutição; Auscultação; Procedimentos clínicos; Acústica; Software; Revisão

\begin{abstract}
Purpose: Describe the instruments used to capture and analyze the acoustic signals obtained from cervical auscultation, and identify those with the greatest potential for application in the speech pathology clinic. Research strategy: This is an integrative literature review. Searches were performed in the MEDLINE/PubMed, Scopus and Web of Science databases in November 2020, using relevant keywords combined with Boolean operators. Selection criteria: Scientific articles published in Portuguese, Spanish or English in the last five years (2016-2020) and that presented a study of cervical auscultation. Results: Ninety-eight articles were found. After the application of selection criteria, 26 articles were selected for this review. Microphones were the most common instruments used to perform cervical auscultation, followed by high-resolution cervical auscultation techniques, which combine acoustic and vibrational signals recorded by a microphone and an accelerometer, respectively. Acoustic analysis was performed using different software packages and/or algorithms depending on the goals of each study. Conclusion: The combination of high-resolution cervical auscultation and machine learning for acoustic analysis has great potential for utilization in the clinical assessment and monitoring of swallowing in speech pathology.
\end{abstract}

Keywords: Deglutition; Auscultation; Critical pathways; Acoustics; Software; Review

\footnotetext{
Trabalho realizado no Curso de Fonoaudiologia da Universidade Federal de Santa Maria - UFSM - Santa Maria (RS), Brasil.

${ }^{1}$ Curso de Fonoaudiologia, Universidade Federal de Santa Maria - UFSM - Santa Maria (RS), Brasil.

${ }^{2}$ Departamento de Fonoaudiologia, Universidade Federal de Santa Maria - UFSM - Santa Maria (RS), Brasil.

Conflito de interesses: Não.

Contribuição dos autores: VD participou da idealização do estudo, coleta, análise e interpretação dos dados e redação do manuscrito; GPB participou da idealização e delineamento do estudo, análise e interpretação dos dados, orientação e redação do manuscrito.

Financiamento: Nada a declarar.

Autor correspondente: Valdani Dias. E-mail: valdanidias@gmail.com

Recebido: Março 31, 2021; Aceito: Maio 05, 2021
} 


\section{INTRODUÇÃO}

A deglutição normal é uma atividade neuromuscular complexa e dinâmica, que depende de um conjunto de comportamentos fisiológicos, controlados pelo sistema nervoso central e periférico. A integridade desses comportamentos resulta no transporte de substâncias sólidas, líquidas e saliva, com eficiência e segurança, da boca até o estômago ${ }^{(1-4)}$.

Os movimentos biomecânicos das diversas estruturas envolvidas antes, durante e após a passagem do bolo alimentar através da faringe produzem os sons da deglutição ${ }^{(5)}$.

Esses sons são descritos, geralmente, como dois ou três cliques distintos, sendo dois cliques audíveis, acompanhados de um sopro expiratório, que acontece imediatamente após a apneia da deglutição ${ }^{(6,7)}$. Já para outros autores, existem três componentes que compreendem os sons da deglutição normal: [1] um sinal fraco associado ao levantamento laríngeo e à passagem do bolo pela faringe; [2] um som forte associado à abertura do cricofaríngeo e [3] um sinal fraco associado à descida da laringe ${ }^{(8,9)}$.

Quando a coordenação dos movimentos é perdida, ocasionando alteração na dinâmica da deglutição em uma ou mais de suas fases, pode-se ter um quadro de disfagia ${ }^{(10)}$. A disfagia não é classificada como doença e sim como sintoma de alguma doença de base que apresenta alta morbidade e mortalidade, podendo levar a inúmeras complicações clínicas, como desidratação, desnutrição, pneumonia, entre outros problemas ${ }^{(4,11)}$.

Existem, atualmente, muitos recursos e métodos tecnológicos disponíveis para avaliação, monitoramento e biofeedback da deglutição $0^{(12)}$, que proporcionam auxílio consistente ao tratamento dos indivíduos ${ }^{(13)}$. Para um diagnóstico preciso, planejamento terapêutico eficaz e melhor definição do prognóstico, considerase fundamental a avaliação clínica da deglutição associada a exames instrumentais complementares, quando necessários ${ }^{(14)}$.

A avaliação clínica da deglutição é constituída pela anamnese, avaliação do sistema sensório-motor oral, avaliação da função mastigatória, da função deglutitória e da fonoarticulação ${ }^{(15)}$. Os exames instrumentais mais utilizados para complementar a avaliação clínica da deglutição são a videofluoroscopia da deglutição (VDF) ${ }^{(10)}$ e a videoendoscopia da deglutição (FEES ${ }^{\circledR}$ - fiberoptic endoscopic evaluation of swallowing) ${ }^{(16)}$. Ainda, outros métodos disponíveis podem ser utilizados como recursos complementares para a avaliação da deglutição, tais como a eletromiografia de superfície (EMGS) ${ }^{(17)}$, a ultrassonografia da deglutição (USG) ${ }^{(18)}$, a oximetria de pulso e a ausculta cervical ${ }^{(14)}$.

Apesar de todas as vantagens de uma avaliação instrumental, os principais métodos utilizados atualmente podem ser de difícil acesso para alguns pacientes, por apresentarem alto custo operacional. Além disso, podem envolver exposição à radiação e procedimentos invasivos ${ }^{(2,19)}$.

Uma opção de baixo custo, fácil acessibilidade, reprodutível e não invasiva em destaque na prática clínica de fonoaudiólogos para avaliação e acompanhamento de pacientes disfágicos é a ausculta cervical. Esse método consiste em ouvir os sons da deglutição por meio de um instrumento de amplificação sonora posicionado no pescoço do paciente ${ }^{(20)}$. Entretanto, a precisão da ausculta é discutível, pois a interpretação dos sinais é subjetiva, tendo em vista o risco de sofrer interferências, tanto das características do instrumento utilizado, quanto da experiência do próprio avaliador ${ }^{(14,21)}$.

A capacidade de digitalizar e gravar o sinal oferece inúmeras possibilidades de processamento e análise das características acústicas dos sons da deglutição. Por essa razão, a utilização de um dispositivo adicional à avaliação, embora não seja comum no cenário clínico, apresenta nítidas vantagens, em comparação à avaliação subjetiva baseada na ausculta cervical realizada com o estetoscópio convencional ${ }^{(22)}$.

Diferentes métodos de ausculta cervical digital, que envolvem instrumentos como acelerômetro ${ }^{(23)}$, estetoscópico eletrônico ${ }^{(24)}$, microfone $^{(25)}$, sensor de emissão acústica ${ }^{(26)}$, sensor piezoelétrico $^{(27)}$ e sensor Doppler ${ }^{(28)}$, vêm sendo estudados nos últimos anos. Esses métodos permitem a digitalização do sinal, viabilizando a análise dos sons da deglutição de forma mais objetiva, a partir de parâmetros como duração, frequência do sinal e amplitude da onda, entre outros aspectos ${ }^{(12,22,29)}$.

A possibilidade de adicionar dados objetivos na análise dos sons da deglutição apresenta-se como um potencial que pode aumentar a precisão das avaliações e favorecer a detecção precoce de riscos, antes que surjam maiores complicações, podendo, também, proporcionar uma economia significativa ao setor de saúde, em razão do baixo custo operacional( ${ }^{(22)}$.

\section{OBJETIVO}

Realizar uma revisão de literatura, a fim de descrever os instrumentos utilizados para captação e análise acústica dos sinais de ausculta cervical e identificar aqueles com maior potencial para aplicação na clínica fonoaudiológica.

\section{ESTRATÉGIA DE PESQUISA}

Este estudo caracteriza-se como uma revisão integrativa da literatura, que consiste na construção de uma análise ampla de pesquisas relevantes e síntese do estado do conhecimento de um determinado assunto, possibilitando a discussão sobre métodos e resultados de pesquisas, o suporte para a tomada de decisões e os avanços na prática clínica, além de reflexões sobre lacunas do conhecimento e a realização de futuros $\operatorname{estudos}^{(30)}$.

Com o propósito de garantir a precisão metodológica do estudo e a validação de seus resultados, foram seguidas as seis fases de construção de uma revisão integrativa da literatura ${ }^{(31)}$, sendo elas: identificação do tema e seleção da questão de pesquisa; estabelecimento dos critérios de inclusão e exclusão; identificação dos estudos pré-selecionados e selecionados; categorização dos estudos selecionados; análise e interpretação dos resultados e, por fim, apresentação da revisão/síntese do conhecimento.

Para nortear a pesquisa bibliográfica, foi elaborada a seguinte questão de investigação para este estudo: "Qual instrumento de captação e de análise acústica dos sinais de ausculta cervical apresenta maior potencial para implementação na prática clínica fonoaudiológica?"

A busca ocorreu no mês de novembro de 2020. Foram consultadas as bases de dados virtuais MEDLINE/PubMed, Scopus e Web of Science (via periódico Capes). A combinação de termos de relevância e operadores booleanos utilizados como estratégia de busca foi: "deglutition" OR "deglutitions" OR "swallow ing" OR "swallowings" $O R$ "swallow" $O R$ "swallows" AND "acoustic analysis" OR "acoustical analysis" OR "auscultation" OR "cervical auscultation" OR "swallowing sounds" OR "swallow sounds" OR "signal processing" OR "acoustics" OR "acoustic" OR "software" 
AND "accelerometry" OR "swallowing accelerometry signals" OR "stethoscope" OR "digital stethoscope" OR "electronic stethoscope" OR "doppler effect" OR "sonar doppler" OR "microphone". A estratégia de busca foi eleita e adaptada de acordo com a codificação e coerência de cada base de dados a ser consultada (Apêndice A).

\section{CRITÉRIOS DE SELEÇÃO}

Para refinamento da pesquisa, foram incluídos somente artigos científicos publicados nos idiomas português, espanhol ou inglês, nos últimos cinco anos (2016-2020) e que apresentassem estudo da ausculta cervical. A decisão de abarcar apenas artigos publicados nos últimos cinco anos objetivou traçar um perfil mais atual sobre o assunto, possibilitando uma reflexão a respeito de estudos futuros.

Foram consideradas como critérios de exclusão as publicações que tivessem conteúdo incompatível com a temática desta revisão, duplicadas ou apresentadas em livros e capítulos de livros, cartas, portarias, editoriais, notícias, resumos de congressos, dissertações e teses.

Inicialmente, realizou-se a leitura criteriosa dos títulos, resumos e palavras-chave de todas as publicações encontradas por meio da estratégia de busca. Foi verificada a adequação dos trabalhos com os critérios de inclusão e exclusão, bem como a correspondência com a questão norteadora do estudo. Quando a leitura dos títulos, resumos e palavras-chave não eram suficientes para definir a seleção de um trabalho, buscava-se a publicação na íntegra.

\section{Análise dos dados}

A sistematização dos artigos selecionados para esta revisão configurou-se a partir da extração e análise das seguintes variáveis: autores e ano de publicação, objetivo da pesquisa, características da amostra, avaliação e procedimentos realizados, métodos de análise acústica e principais resultados e conclusões apresentados. Essas informações foram estruturadas em uma matriz de síntese (Quadro 1) elaborada no software Microsoft Office - Excel ${ }^{\circledR}$, subdividida em nove categorias analíticas, de acordo com os instrumentos de avaliação utilizados na captação dos sinais de ausculta cervical da deglutição: acelerômetro; estetoscópio eletrônico; microfone; microfone e acelerômetro; microfone e sensor de emissão acústica; microfone, sensor Doppler e estetoscópio; sensor Doppler e microfone; sensor Doppler; sensor piezoelétrico.

As etapas de busca, seleção e sistematização inicial dos artigos foram realizadas por uma das autoras. Quando ela teve dúvidas quanto à adequação de artigos pré-selecionados aos critérios de inclusão e exclusão do estudo, os artigos foram relidos na íntegra por ambas as pesquisadoras, que avaliaram e estabeleceram um consenso sobre a seleção.

\section{RESULTADOS}

Foram encontrados 98 artigos por meio das estratégias de buscas nas bases de dados, sendo 22 na MEDLINE/PubMed, 34 na Scopus e 42 na Web of Science. Após análise e aplicação dos critérios de inclusão e exclusão, foram selecionados 26 artigos para o estudo (Figura 1).

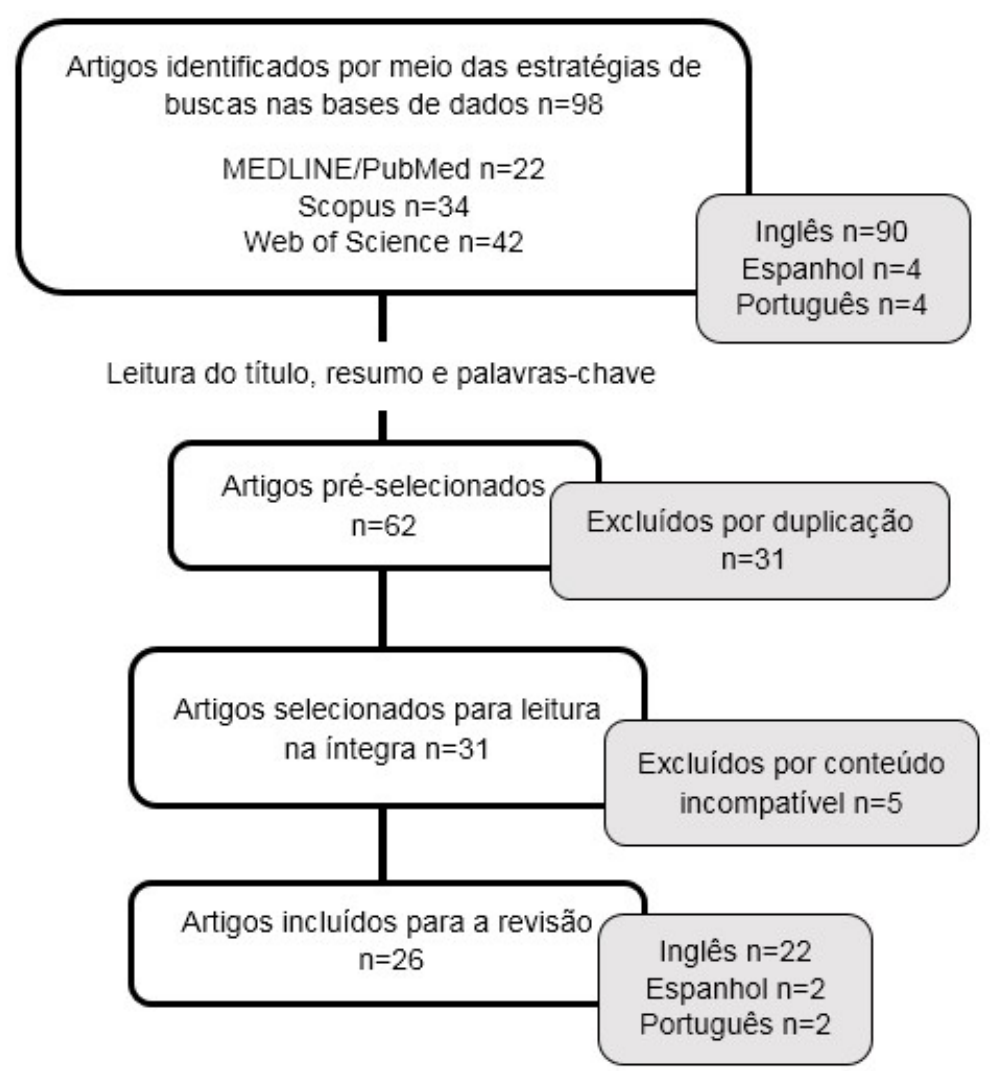

Figura 1. Fluxograma da seleção dos artigos

Legenda: $\mathrm{n}=$ número de estudos 
Quadro 1. Sistematização dos artigos selecionados na revisão

\begin{tabular}{|c|c|c|c|c|c|}
\hline Autores & Objetivo & Amostra & $\begin{array}{c}\text { Avaliação/ } \\
\text { procedimentos }\end{array}$ & Análise acústica & Principais resultados e conclusões \\
\hline \multicolumn{6}{|c|}{ Acelerômetro } \\
\hline Steele et al. ${ }^{(23)}$ & $\begin{array}{l}\text { Desenvolver } \\
\text { algoritmos para } \\
\text { detectar problemas de } \\
\text { deglutição, usando um } \\
\text { sistema baseado em } \\
\text { acelerômetro. }\end{array}$ & $\begin{array}{l}305 \text { indivíduos com } \\
\text { AVC, outras lesões } \\
\text { cerebrais ou risco } \\
\text { para disfagia. }\end{array}$ & $\begin{array}{l}\text { Ausculta cervical com } \\
\text { um acelerômetro de } \\
\text { eixo duplo. } \\
\text { Exame de VFD. }\end{array}$ & $\begin{array}{l}\text { Algoritmos } \\
\text { desenvolvidos pelos } \\
\text { autores. }\end{array}$ & $\begin{array}{l}\text { O sistema criado permitiu identificar } \\
\text { alteração na deglutição de líquidos } \\
\text { finos com alta precisão (sensibilidade } \\
90,4 \% \text {; especificidade } 60,0 \% \text { ). } \\
\text { Os algoritmos representam uma } \\
\text { primeira etapa do desenvolvimento } \\
\text { de um dispositivo baseado em } \\
\text { acelerometria para triagem de } \\
\text { deglutição. }\end{array}$ \\
\hline \multicolumn{6}{|c|}{ Estetoscópio eletrônico } \\
\hline $\begin{array}{l}\text { Sánchez- } \\
\text { Cardona et al. }{ }^{(21)}\end{array}$ & $\begin{array}{l}\text { Caracterizar e } \\
\text { classificar os sinais } \\
\text { de ausculta cervical e } \\
\text { discriminar os sons da } \\
\text { deglutição daqueles } \\
\text { associados ao ruído. }\end{array}$ & $\begin{array}{l}10 \text { indivíduos } \\
\text { saudáveis ( } 6 \text { homens; } \\
\text { média de idade } 27,3 \\
\text { anos). }\end{array}$ & $\begin{array}{l}\text { Ausculta cervical } \\
\text { com um estetoscópio } \\
\text { eletrônico (E-scope® } \\
\text { Cardionics). }\end{array}$ & $\begin{array}{l}\text { Algoritmos } \\
\text { selecionados e de } \\
\text { aprendizado de } \\
\text { máquina. }\end{array}$ & $\begin{array}{l}\text { O método proposto permitiu a } \\
\text { classificação dos sons da deglutição } \\
\text { por meio de um estetoscópio. } \\
\text { Apresentou acurácia de } 97,7 \% \text { para } \\
\text { detecção de eventos acústicos e } 91,7 \% \\
\text { para sons de deglutição por fechamento } \\
\text { glótico, na presença de fontes de ruído. }\end{array}$ \\
\hline García $^{(24)}$ & $\begin{array}{l}\text { Embasar os } \\
\text { processos avaliativos } \\
\text { da ausculta } \\
\text { cervical a partir da } \\
\text { estruturação do perfil } \\
\text { espectrográfico da } \\
\text { fase faríngea. }\end{array}$ & $\begin{array}{l}93 \text { indivíduos } \\
\text { saudáveis, maiores de } \\
18 \text { anos. }\end{array}$ & $\begin{array}{l}\text { Ausculta cervical } \\
\text { com um estetoscópio } \\
\text { eletrônico (Littman® } \\
3200) \text {. }\end{array}$ & Software StethAssist. & $\begin{array}{l}\text { O perfil espectrográfico da fase faríngea } \\
\text { representou quatro eventos da deglutição } \\
\text { que podem ser analisados a partir dos } \\
\text { tempos obtidos na análise digital da } \\
\text { onda acústica. Dessa forma, forneceu } \\
\text { parâmetros de interpretação funcional da } \\
\text { deglutição. }\end{array}$ \\
\hline \multicolumn{6}{|c|}{ Microfone } \\
\hline $\mathrm{Bi}$ et al. ${ }^{(32)}$ & $\begin{array}{l}\text { Monitorar a ingestão } \\
\text { diária de alimentos } \\
\text { de forma precisa } \\
\text { e conveniente por } \\
\text { meio do sistema } \\
\text { AutoDietary } \\
\text { desenvolvido. }\end{array}$ & 12 indivíduos. & $\begin{array}{l}\text { Ausculta cervical } \\
\text { com um microfone de } \\
\text { garganta. }\end{array}$ & $\begin{array}{l}\text { Aplicativo de } \\
\text { smartphone. }\end{array}$ & $\begin{array}{l}\text { A acurácia média do reconhecimento do } \\
\text { tipo de alimento pelo AutoDietary foi de } \\
84,9 \% \text {, e de até } 97,6 \% \text { para classificar a } \\
\text { ingestão de alimentos líquidos e } 99,7 \% \\
\text { sólidos. } \\
\text { O AutoDietary se apresentou como } \\
\text { um dispositivo promissor para o } \\
\text { reconhecimento da ingestão alimentar na } \\
\text { vida diária. }\end{array}$ \\
\hline Honda et al. ${ }^{(33)}$ & $\begin{array}{l}\text { Caracterizar e } \\
\text { identificar o processo } \\
\text { de geração do som } \\
\text { durante a deglutição } \\
\text { em adultos jovens e } \\
\text { saudáveis. }\end{array}$ & $\begin{array}{l}33 \text { jovens e saudáveis, } \\
\text { subdivididos em três } \\
\text { grupos experimentais: } \\
\text { 1) } 10 \text { homens e } 10 \\
\text { mulheres, com média } \\
\text { de idade } 25,8 \text { anos; } \\
\text { 2) } 5 \text { homens e } 5 \\
\text { mulheres, com média } \\
\text { de idade } 28,0 \text { anos; } \\
\text { 3) } 3 \text { homens, com } \\
\text { média de idade } 27,6 \\
\text { anos. }\end{array}$ & $\begin{array}{l}\text { Ausculta cervical } \\
\text { com um microfone } \\
\text { condensador. } \\
\text { Registro simultâneo } \\
\text { da VFD na experiência } \\
\text { 3. }\end{array}$ & Software DADiSP. & $\begin{array}{l}\text { O som da deglutição pode ser dividido } \\
\text { em três períodos: } \\
\text { Fase oral: movimento posterior da } \\
\text { língua e do osso hioide; } \\
\text { Fase faríngea: movimento laríngeo, } \\
\text { elevação do osso hioide, fechamento } \\
\text { da epiglote e passagem do bolo para } \\
\text { o esôfago; } \\
\text { - Fase de reposicionamento do osso } \\
\text { hioide e da laringe e a reabertura da } \\
\text { epiglote. }\end{array}$ \\
\hline Frakking et al. ${ }^{(25)}$ & $\begin{array}{l}\text { Estabelecer } \\
\text { perfis acústicos e } \\
\text { perceptuais dos sons } \\
\text { da deglutição com e } \\
\text { sem aspiração, em } \\
\text { crianças com disfagia, } \\
\text { e determinar se } \\
\text { existe diferença entre } \\
\text { esses dois tipos de } \\
\text { deglutição. }\end{array}$ & $\begin{array}{l}47 \text { crianças ( } 57 \% \text { do } \\
\text { sexo masculino). }\end{array}$ & $\begin{array}{l}\text { Ausculta cervical } \\
\text { com um microfone } \\
\text { condensador } \\
\text { omnidirecional. } \\
\text { Exame de VFD. }\end{array}$ & $\begin{array}{l}\text { Software Adobe } \\
\text { Audition. } \\
\text { Software Matlab. }\end{array}$ & $\begin{array}{l}\text { A presença de um som de liberação } \\
\text { glótica junto a sons respiratórios } \\
\text { normais após a deglutição são possíveis } \\
\text { indicadores de uma deglutição não } \\
\text { aspirativa. Por outro lado, a presença } \\
\text { de respiração ruidosa e um ou mais } \\
\text { dos sons de tosse, chiado, estertores, } \\
\text { pigarro e estridor são indicativos de } \\
\text { aspiração da deglutição, quando } \\
\text { comparados à VFD. }\end{array}$ \\
\hline Kamiyanagi et al. ${ }^{(34)}$ & $\begin{array}{l}\text { Avaliar a capacidade } \\
\text { de deglutição } \\
\text { em pacientes } \\
\text { maxilectomizados, } \\
\text { com e sem a prótese } \\
\text { obturadora colocada. }\end{array}$ & $\begin{array}{l}27 \text { pacientes com } \\
\text { maxilectomia ( } 15 \\
\text { homens; média de } \\
\text { idade } 66 \text { anos); } 30 \\
\text { controles saudáveis } \\
\text { ( } 14 \text { homens; média de } \\
\text { idade } 44,9 \text { anos). }\end{array}$ & $\begin{array}{l}\text { Ausculta cervical } \\
\text { com um microfone } \\
\text { condensador de } \\
\text { eletreto. }\end{array}$ & $\begin{array}{l}\text { Software } \\
\text { Computerized Speech } \\
\text { Lab. }\end{array}$ & $\begin{array}{l}\text { Observaram-se diferenças significativas, } \\
\text { principalmente na medida de duração } \\
\text { do pico de intensidade de variáveis } \\
\text { analisadas inter e intragrupos. } \\
\text { A habilidade de deglutição em pacientes } \\
\text { com maxilectomia pode ser melhorada } \\
\text { com o uso de uma prótese obturadora. }\end{array}$ \\
\hline Li et al. ${ }^{(35)}$ & $\begin{array}{l}\text { Caracterizar o } \\
\text { padrão temporal da } \\
\text { língua, do hioide e } \\
\text { dos músculos supra } \\
\text { e infra-hioideos e } \\
\text { determinar como eles } \\
\text { estão relacionados e } \\
\text { coordenados. }\end{array}$ & $\begin{array}{l}15 \text { homens saudáveis } \\
\text { (média de idade } 27,7 \\
\text { anos). }\end{array}$ & $\begin{array}{l}\text { Sistema de detecção } \\
\text { composto por um } \\
\text { sensor de pressão, um } \\
\text { sensor de curvatura, } \\
\text { eletrodos de superfície } \\
\text { e um microfone. }\end{array}$ & $\begin{array}{l}\text { Nenhum método } \\
\text { descrito. }\end{array}$ & $\begin{array}{l}\text { Foram confirmadas correlações } \\
\text { significativas entre os músculos } \\
\text { relacionados à deglutição, pressão da } \\
\text { língua e hioide. } \\
\text { O sistema de detecção não invasivo tem } \\
\text { potencial como um bom contribuinte para } \\
\text { monitorar e avaliar a fase orofaríngea da } \\
\text { deglutição. }\end{array}$ \\
\hline
\end{tabular}

Legenda: $\mathrm{AVC}$ = Acidente vascular cerebral; VFD = Videofluoroscopia da deglutição; Gráficos Q-Q = gráficos quantil-quantil de distribuição de probabilidade 
Quadro 1. Continuação...

\begin{tabular}{|c|c|c|c|c|c|}
\hline Autores & Objetivo & Amostra & $\begin{array}{c}\text { Avaliação/ } \\
\text { procedimentos }\end{array}$ & Análise acústica & Principais resultados e conclusões \\
\hline Frakking et al. ${ }^{(36)}$ & $\begin{array}{l}\text { Obter dados } \\
\text { normativos dos } \\
\text { parâmetros acústicos } \\
\text { da deglutição e } \\
\text { determinar se eles } \\
\text { se relacionam com } \\
\text { a idade. Obter sinais } \\
\text { clínicos perceptivos } \\
\text { dos sons respiratórios } \\
\text { e de deglutição pré, } \\
\text { durante e após a } \\
\text { deglutição. }\end{array}$ & $\begin{array}{l}74 \text { crianças saudáveis, } \\
\text { entre } 4 \text { e } 36 \text { meses } \\
\text { ( } 35 \text { homens; média de } \\
\text { idade } 17,1 \text { meses). }\end{array}$ & $\begin{array}{l}\text { Ausculta cervical } \\
\text { com um microfone } \\
\text { condensador } \\
\text { omnidirecional. } \\
\text { Um gravador de vídeo } \\
\text { digital para visualizar } \\
\text { o movimento } \\
\text { laríngeo associado à } \\
\text { deglutição. }\end{array}$ & $\begin{array}{l}\text { Software Adobe } \\
\text { Audition. } \\
\text { Software Matlab. }\end{array}$ & $\begin{array}{l}\text { Os sons da deglutição tornam-se } \\
\text { mais altos à medida que as crianças } \\
\text { ficam mais velhas, e, com os sólidos } \\
\text { mastigáveis, ficam mais curtos. } \\
\text { A maioria das crianças tem sons } \\
\text { respiratórios normais antes e depois da } \\
\text { deglutição. Um número muito pequeno } \\
\text { apresenta tosse única ocasional com } \\
\text { fluídos finos, dita como normal ao } \\
\text { processo de aprendizagem e controle dos } \\
\text { fluxos e volumes dos alimentos. }\end{array}$ \\
\hline Almeida et al. ${ }^{(37)}$ & $\begin{array}{l}\text { Caracterizar o sinal } \\
\text { acústico da aspiração } \\
\text { traqueal silenciosa em } \\
\text { crianças com disfagia } \\
\text { orofaríngea. }\end{array}$ & $\begin{array}{l}18 \text { crianças ( } 56 \% \\
\text { meninas, idade } \\
\text { mediana de } 6 \text { anos). } \\
\text { Grupos: } 8 \text { que } \\
\text { aspiram e } 10 \text { que não } \\
\text { aspiram. }\end{array}$ & $\begin{array}{l}\text { Ausculta cervical } \\
\text { com um microfone } \\
\text { condensador de } \\
\text { eletreto. } \\
\text { Exame de VFD. }\end{array}$ & Software Raven. & $\begin{array}{l}\text { A curva de densidade de potência } \\
\text { espectral de deglutições com aspiração } \\
\text { apresentou um padrão ascendente, } \\
\text { enquanto a curva das deglutições } \\
\text { normais foi plana. } \\
\text { A técnica não invasiva identificou a } \\
\text { aspiração por um aumento da curva de } \\
\text { densidade de potência espectral nos } \\
\text { sons aspirados. }\end{array}$ \\
\hline Kurihara et al. ${ }^{(38)}$ & $\begin{array}{l}\text { Desenvolver } \\
\text { um dispositivo } \\
\text { de detecção de } \\
\text { movimento de } \\
\text { deglutição e um } \\
\text { sistema de estimativa } \\
\text { de estado de } \\
\text { deglutição. }\end{array}$ & $\begin{array}{l}7 \text { homens saudáveis } \\
\text { (média de idade } 22 \\
\text { anos; de altura: } 175,1 \\
\mathrm{~cm} \text {; de peso: } 61,6 \mathrm{~kg} \text { ). }\end{array}$ & $\begin{array}{l}\text { Dispositivo } \\
\text { compreende } \\
\text { um microfone } \\
\text { condensador de } \\
\text { eletreto bidirecional } \\
\text { e tubo de ar. O } \\
\text { experimento incluiu } \\
\text { f1 (engolir nada), } \\
\text { f2 (chá), f3 (chá } \\
\text { espessado) e f } 4 \text { (bolo } \\
\text { de arroz). }\end{array}$ & Software Matlab. & $\begin{array}{l}\text { À medida que a viscosidade aumentou, } \\
\text { a laringe exibiu movimentos complexos } \\
\text { para engolir o alimento. Esses } \\
\text { movimentos foram refletidos no sinal. } \\
\text { O método proposto foi validado com base } \\
\text { na estimativa de } f 1 \text { - } f 4 \text {, e as acurácias de } \\
0,99,0,81,0,84 \text { e } 0,91 \text {, respectivamente, } \\
\text { foram alcançadas. }\end{array}$ \\
\hline Miyagi et al. ${ }^{(39)}$ & $\begin{array}{l}\text { Investigar o uso } \\
\text { do aprendizado } \\
\text { de máquina para } \\
\text { classificar os sons } \\
\text { da deglutição como: } \\
\text { normal, ou disfagia } \\
\text { leve, moderada e } \\
\text { grave. }\end{array}$ & $\begin{array}{l}17 \text { homens e } 10 \\
\text { mulheres saudáveis } \\
\text { (média de idade } 22,4 \text { ); } \\
78 \text { homens e } 65 \\
\text { mulheres disfágicos } \\
\text { (média de idade } 83,3 \text { ). }\end{array}$ & $\begin{array}{l}\text { Ausculta cervical } \\
\text { com um microfone de } \\
\text { garganta. }\end{array}$ & $\begin{array}{l}\text { Software Audacity } \\
\text { e algoritmo de } \\
\text { aprendizado de } \\
\text { máquina. }\end{array}$ & $\begin{array}{l}\text { Em indivíduos normais e disfágicos, a } \\
\text { medida } \mathrm{F} \text { máxima foi de } 78,9 \% \text {. } \\
\text { Para sujeitos normais e disfágicos } \\
\text { de graus leve, moderado e grave, } \\
\text { os valores da medida } \mathrm{F} \text { foram } \\
65,6 \%, 53,1 \%, 51,1 \% \text { e } 37,1 \% \text {, } \\
\text { respectivamente, insuficientes para } \\
\text { usar o classificador como um método } \\
\text { independente para o diagnóstico. }\end{array}$ \\
\hline \multicolumn{6}{|c|}{ Microfone e Acelerômetro - Ausculta Cervical de Alta Resolução } \\
\hline Dudik et al. ${ }^{(40)}$ & $\begin{array}{l}\text { Caracterizar os sinais } \\
\text { da ausculta cervical } \\
\text { de indivíduos com } \\
\text { disfagia que aspiram. }\end{array}$ & $\begin{array}{l}76 \text { adultos ( } 50 \\
\text { homens; média de } \\
\text { idade } 62 \text { anos), } 17 \\
\text { com diagnóstico de } \\
\text { acidente vascular } \\
\text { cerebral (AVC), } \\
59 \text { com outras } \\
\text { condições médicas. }\end{array}$ & $\begin{array}{l}\text { Ausculta cervical } \\
\text { com um acelerômetro } \\
\text { triaxial e um microfone } \\
\text { de contato. } \\
\text { Exame de VFD. }\end{array}$ & $\begin{array}{l}\text { Software LabView } \\
\text { e algoritmos } \\
\text { selecionados. }\end{array}$ & $\begin{array}{l}\text { Foram apresentadas poucas diferenças } \\
\text { entre as deglutições seguras e } \\
\text { inseguras com base nas características } \\
\text { escolhidas. } \\
\text { Vários recursos estatísticos devem } \\
\text { ser usados simultaneamente quando } \\
\text { a aspiração for escolhida como uma } \\
\text { variável em trabalhos futuros. }\end{array}$ \\
\hline Movahedi et al. ${ }^{(41)}$ & $\begin{array}{l}\text { Investigar se os } \\
\text { sinais da deglutição } \\
\text { registrados por um } \\
\text { microfone e um } \\
\text { acelerômetro triaxial } \\
\text { diferem entre si ou } \\
\text { carregam informações } \\
\text { exclusivas sobre a } \\
\text { função de deglutição. }\end{array}$ & $\begin{array}{l}72 \text { participantes ( } 42 \\
\text { homens; média de } \\
\text { idade } 63 \text {, anos), } \\
\text { desses, } 20 \mathrm{com} \\
\text { histórico de AVC. }\end{array}$ & $\begin{array}{l}\text { Ausculta cervical } \\
\text { com um acelerômetro } \\
\text { triaxial e um microfone } \\
\text { de contato. } \\
\text { Exame de VFD. }\end{array}$ & $\begin{array}{l}\text { Software LabView } \\
\text { e algoritmos } \\
\text { selecionados. }\end{array}$ & $\begin{array}{l}\text { Embora os sons e as vibrações da } \\
\text { deglutição possam ter as mesmas } \\
\text { fontes fisiológicas, os sinais da } \\
\text { deglutição registrados pelo microfone e } \\
\text { pelo acelerômetro diferiram entre si nos } \\
\text { domínios do tempo e da frequência. As } \\
\text { informações fornecidas pelos sons e } \\
\text { pelas vibrações da deglutição não são } \\
\text { intercambiáveis. }\end{array}$ \\
\hline Dudik et al. ${ }^{(42)}$ & $\begin{array}{l}\text { Desenvolver } \\
\text { um método de } \\
\text { investigação } \\
\text { das alterações } \\
\text { de deglutição, } \\
\text { e caracterizar } \\
\text { e comparar as } \\
\text { deglutições de } \\
\text { pacientes saudáveis e } \\
\text { não saudáveis. }\end{array}$ & $\begin{array}{l}\text { Grupo controle: } 55 \\
\text { indivíduos saudáveis } \\
\text { ( } 28 \text { homens; média de } \\
\text { idade } 39 \text { anos). } \\
\text { Grupo estudo: } 53 \\
\text { pacientes com } \\
\text { suspeita de disfagia: } \\
13 \text { ( } 10 \text { homens; média } \\
\text { de idade } 66 \text { anos) } \\
\text { com diagnóstico } \\
\text { atual de AVC e } 40 \\
\text { ( } 24 \text { homens; média } \\
\text { de idade } 62 \text { anos) } \\
\text { com outras condições } \\
\text { médicas. }\end{array}$ & $\begin{array}{l}\text { Ausculta cervical } \\
\text { com um acelerômetro } \\
\text { triaxiale um microfone } \\
\text { de contato. } \\
\text { Grupo estudo: exame } \\
\text { de VFD. }\end{array}$ & $\begin{array}{l}\text { Software LabView } \\
\text { e algoritmos } \\
\text { selecionados. }\end{array}$ & $\begin{array}{l}\text { Quase todos os recursos escolhidos } \\
\text { para vibrações e sons mostraram } \\
\text { diferenças significativas entre as } \\
\text { deglutições saudáveis e as não } \\
\text { saudáveis, apesar da ausência de } \\
\text { aspiração. } \\
\text { Os achados devem colaborar } \\
\text { com o campo da ausculta cervical } \\
\text { e servir como referência para } \\
\text { investigações futuras sobre métodos de } \\
\text { caracterização mais especializados. }\end{array}$ \\
\hline
\end{tabular}

Legenda: AVC = Acidente vascular cerebral; VFD = Videofluoroscopia da deglutição; Gráficos Q-Q = gráficos quantil-quantil de distribuição de probabilidade 
Quadro 1. Continuação...

\begin{tabular}{|c|c|c|c|c|c|}
\hline Autores & Objetivo & Amostra & $\begin{array}{c}\text { Avaliação/ } \\
\text { procedimentos }\end{array}$ & Análise acústica & Principais resultados e conclusões \\
\hline Rebrion et al. ${ }^{(43)}$ & $\begin{array}{l}\text { Comparar o } \\
\text { deslocamento } \\
\text { do osso hioide a } \\
\text { partir de imagens } \\
\text { de VFD, com as } \\
\text { características do } \\
\text { sinal da ausculta. }\end{array}$ & $\begin{array}{l}25 \text { pacientes ( } 12 \\
\text { homens; média de } \\
\text { idade } 60 \text { anos). }\end{array}$ & $\begin{array}{l}\text { Ausculta cervical } \\
\text { com um acelerômetro } \\
\text { triaxial e um microfone } \\
\text { de contato. } \\
\text { Exame de VFD. }\end{array}$ & $\begin{array}{l}\text { Software LabView } \\
\text { e algoritmos } \\
\text { selecionados. }\end{array}$ & $\begin{array}{l}\text { Os sons e vibrações da deglutição } \\
\text { estão relacionados aos movimentos } \\
\text { horizontais e verticais das partes } \\
\text { anterior e posterior do osso hioide. }\end{array}$ \\
\hline Kurosu et al. ${ }^{(44)}$ & $\begin{array}{l}\text { Examinar se existe } \\
\text { associação entre os } \\
\text { sinais acústicos da } \\
\text { ausculta cervical de } \\
\text { alta resolução e os } \\
\text { eventos cinemáticos } \\
\text { da deglutição. }\end{array}$ & $\begin{array}{l}35 \text { pacientes com AVC } \\
\text { e suspeita de disfagia } \\
\text { ( } 26 \text { homens; média de } \\
\text { idade } 65,8 \text { anos). }\end{array}$ & $\begin{array}{l}\text { Ausculta cervical } \\
\text { com um acelerômetro } \\
\text { triaxial e um microfone } \\
\text { de contato. } \\
\text { Exame de VFD. }\end{array}$ & $\begin{array}{l}\text { Software LabView } \\
\text { e algoritmos } \\
\text { selecionados. }\end{array}$ & $\begin{array}{l}\text { Existe uma forte relação entre } \\
\text { os sinais de ausculta cervical de } \\
\text { alta resolução e vários eventos } \\
\text { cinemáticos da deglutição (abertura } \\
\text { do esfíncter esofágico superior; } \\
\text { fechamento do vestíbulo laríngeo; } \\
\text { reabertura do vestíbulo laríngeo; início, } \\
\text { deslocamento máximo e repouso do } \\
\text { hioide). } \\
\text { Há potencial desse método de } \\
\text { ausculta cervical ser desenvolvido para } \\
\text { diagnóstico e tratamento clínico de } \\
\text { reabilitação da disfagia. }\end{array}$ \\
\hline Donohue et al. ${ }^{(45)}$ & $\begin{array}{l}\text { Investigar a } \\
\text { capacidade da } \\
\text { ausculta cervical } \\
\text { de alta resolução } \\
\text { de rastrear o } \\
\text { deslocamento do } \\
\text { osso hioide durante a } \\
\text { deglutição. }\end{array}$ & $\begin{array}{l}114 \text { pacientes ( } 65 \\
\text { homens; idades entre } \\
19 \text { e } 94 \text { anos) com } \\
\text { suspeita /confirmação } \\
\text { de disfagia; } \\
16 \text { adultos saudáveis. }\end{array}$ & $\begin{array}{l}\text { Ausculta cervical } \\
\text { com um acelerômetro } \\
\text { triaxial e um microfone } \\
\text { de contato. } \\
\text { Exame de VFD. }\end{array}$ & $\begin{array}{l}\text { Software LabView } \\
\text { e algoritmos de } \\
\text { aprendizado de } \\
\text { máquina. }\end{array}$ & $\begin{array}{l}\text { Os algoritmos de aprendizado de } \\
\text { máquina conseguiram localizar } \\
\text { aproximadamente metade ( } 51 \% \text { do } \\
\text { conjunto de dados do paciente, } 49,9 \% \\
\text { do conjunto de dados saudável) do } \\
\text { corpo hioide em cada quadro dos } \\
\text { segmentos da deglutição. } \\
\text { Há possibilidade de rastreamento } \\
\text { preciso e automatizado do } \\
\text { deslocamento do osso hioide a partir } \\
\text { de sinais de ausculta cervical de alta } \\
\text { resolução sem o uso de imagens de } \\
\text { VFD. }\end{array}$ \\
\hline Donohue et al. ${ }^{(46)}$ & $\begin{array}{l}\text { Saber se os sinais } \\
\text { de ausculta cervical } \\
\text { de alta resolução } \\
\text { podem diferenciar } \\
\text { entre deglutições de } \\
\text { pessoas saudáveis } \\
\text { e de pessoas } \\
\text { com doenças } \\
\text { neurodegenerativas. }\end{array}$ & $\begin{array}{l}20 \text { pacientes } \\
\text { com doenças } \\
\text { neurodegenerativas } \\
\text { ( } 10 \text { homens; média de } \\
\text { idade } 61,25 \text { anos); } \\
51 \text { adultos saudáveis } \\
\text { ( } 22 \text { homens; média de } \\
\text { idade } 67,21 \text { anos). }\end{array}$ & $\begin{array}{l}\text { Ausculta cervical } \\
\text { com um acelerômetro } \\
\text { triaxial e um microfone } \\
\text { de contato. } \\
\text { Exame de VFD. }\end{array}$ & $\begin{array}{l}\text { Software LabView } \\
\text { e algoritmos de } \\
\text { aprendizado de } \\
\text { máquina. }\end{array}$ & $\begin{array}{l}\text { Características do sinal de } \\
\text { ausculta cervical de alta resolução } \\
\text { combinadas a métodos estatísticos e } \\
\text { técnicas de aprendizado de máquina } \\
\text { podem diferenciar efetivamente } \\
\text { as deglutições de pessoas } \\
\text { saudáveis daquelas de pessoas } \\
\text { com doenças neurodegenerativas, } \\
\text { com um alto grau de precisão } \\
(99 \%) \text {, sensibilidade (100\%) e } \\
\text { especificidade (99\%). }\end{array}$ \\
\hline \multicolumn{6}{|c|}{ Microfone e Sensor de Emissão Acústica } \\
\hline Kamiyanagi et al..$^{(47)}$ & $\begin{array}{l}\text { Estabelecer um } \\
\text { método de avaliação } \\
\text { da deglutição que } \\
\text { possa ser utilizado } \\
\text { para triagem com } \\
\text { confiabilidade. }\end{array}$ & $\begin{array}{l}6 \text { homens saudáveis } \\
\text { (média de idade } 40,2 \\
\text { anos) e } 6 \text { homens } \\
\text { com prótese de } \\
\text { aumento palatino } \\
\text { (média de idade } 72,1 \\
\text { anos). }\end{array}$ & $\begin{array}{l}\text { Ausculta cervical } \\
\text { com um microfone } \\
\text { condensador de } \\
\text { garganta e um sensor } \\
\text { de emissão acústica. }\end{array}$ & $\begin{array}{l}\text { Software Sound it! } \\
\text { Premium e algoritmos } \\
\text { selecionados. }\end{array}$ & $\begin{array}{l}\text { O tempo de duração do som da } \\
\text { deglutição medido pelo microfone foi } \\
\text { significativamente mais alto em pacientes } \\
\text { com prótese de aumento palatino. } \\
\text { O sensor de emissão acústica permitiu } \\
\text { a medição de faixas de alta frequência } \\
\text { que não podiam ser medidas com o } \\
\text { microfone. } \\
\text { Os achados sugeriram a validação da } \\
\text { análise do som da deglutição com base } \\
\text { nas distribuições de probabilidade por } \\
\text { meio de gráficos } Q-Q \text {. }\end{array}$ \\
\hline Chikai et al. ${ }^{(26)}$ & $\begin{array}{l}\text { Propor um sistema } \\
\text { de medição de sons } \\
\text { da deglutição que } \\
\text { emprega um sensor } \\
\text { capaz de adquirir } \\
\text { informações acústicas } \\
\text { em uma ampla faixa } \\
\text { de frequência. }\end{array}$ & $\begin{array}{l}1 \text { indivíduo saudável } \\
\text { do sexo masculino } \\
\text { (idade: } 29 \text { anos). }\end{array}$ & $\begin{array}{l}\text { Ausculta cervical } \\
\text { com um microfone } \\
\text { condensador de } \\
\text { garganta e um sensor } \\
\text { de emissão acústica. }\end{array}$ & $\begin{array}{l}\text { Software Adobe } \\
\text { Audition e algoritmos } \\
\text { selecionados. }\end{array}$ & $\begin{array}{l}\text { O sensor de emissão acústica } \\
\text { exibiu sinais acústicos superiores } 3 \\
\mathrm{KHz} \text {, o que não foi possível com o } \\
\text { microfone. } \\
\text { Os dados medidos com o sensor } \\
\text { de emissão acústica refletiram de } \\
\text { forma mais sensível e, combinados } \\
\text { aos gráficos Q-Q, apresentaram } \\
\text { potencial para distinguir a diferença } \\
\text { na viscosidade da amostra. }\end{array}$ \\
\hline
\end{tabular}

Legenda: AVC = Acidente vascular cerebral; VFD = Videofluoroscopia da deglutição; Gráficos Q-Q = gráficos quantil-quantil de distribuição de probabilidade 
Quadro 1. Continuação...

\begin{tabular}{|c|c|c|c|c|c|}
\hline Autores & Objetivo & Amostra & $\begin{array}{c}\text { Avaliação/ } \\
\text { procedimentos }\end{array}$ & Análise acústica & Principais resultados e conclusões \\
\hline \multicolumn{6}{|c|}{ Microfone, Sensor Doppler e Estetoscópio } \\
\hline \multicolumn{6}{|c|}{ Sensor Doppler e microfone } \\
\hline \multicolumn{6}{|c|}{ Sensor Doppler } \\
\hline Soria et al. ${ }^{(13)}$ & $\begin{array}{l}\text { Comparar os } \\
\text { parâmetros acústicos } \\
\text { da deglutição } \\
\text { orofaríngea entre } \\
\text { faixas etárias distintas. }\end{array}$ & $\begin{array}{l}\text { Grupo I: } 75 \text { idosos } \\
\text { saudáveis (média de } \\
\text { idade } 71 \text { anos). } \\
\text { Grupo II: } 72 \text { adultos } \\
\text { saudáveis (média de } \\
\text { idade } 42 \text { anos). }\end{array}$ & $\begin{array}{l}\text { Sinal sonoro } \\
\text { capturado pelo sonar } \\
\text { Doppler. }\end{array}$ & Software VoxMetria. & $\begin{array}{l}\text { Houve modificação do padrão acústico } \\
\text { da deglutição, tanto em relação à } \\
\text { consistência quanto ao volume do bolo } \\
\text { alimentar, quando comparados idosos } \\
\text { e adultos. A característica principal } \\
\text { encontrada nos idosos foi uma curva } \\
\text { com menor amplitude e maior tempo } \\
\text { que nos adultos. }\end{array}$ \\
\hline \multicolumn{6}{|c|}{ Sensor Piezoelétrico } \\
\hline Yagi et al.(27) & $\begin{array}{l}\text { Avaliar a eficiência e } \\
\text { eficácia de um sistema } \\
\text { de monitoramento da } \\
\text { deglutição que usa } \\
\text { fluxo respiratório, o } \\
\text { som da deglutição e o } \\
\text { movimento laríngeo. }\end{array}$ & $\begin{array}{l}11 \text { indivíduos } \\
\text { saudáveis ( } 9 \text { homens; } \\
\text { média de idade } 40,1 \\
\text { anos); } \\
10 \text { pacientes com } \\
\text { disfagia ( } 4 \text { homens; } \\
\text { média de idade, } 75,6 \\
\text { anos). }\end{array}$ & $\begin{array}{l}\text { O sistema } \\
\text { compreende sensor } \\
\text { de fluxo do tipo cânula } \\
\text { nasal e um sensor } \\
\text { piezoelétrico. } \\
\text { Exame de VFD. }\end{array}$ & $\begin{array}{l}\text { Software Matlab } \\
\text { e algoritmos } \\
\text { selecionados. }\end{array}$ & $\begin{array}{l}\text { O tempo de retardo de elevação e o } \\
\text { tempo de elevação laríngea foram } \\
\text { significativamente prolongados em } \\
\text { pacientes com disfagia, principalmente } \\
\text { em alimentos com maior viscosidade. } \\
\text { A taxa de ocorrência do padrão } \\
\text { inspiração-deglutição aumentou } \\
\text { significativamente no grupo de } \\
\text { pacientes. } \\
\text { O dispositivo pode facilitar a avaliação } \\
\text { de alguns aspectos da disfunção } \\
\text { da deglutição, principalmente a } \\
\text { coordenação entre a deglutição e a } \\
\text { respiração. }\end{array}$ \\
\hline
\end{tabular}

Legenda: AVC = Acidente vascular cerebral; VFD = Videofluoroscopia da deglutição; Gráficos Q-Q = gráficos quantil-quantil de distribuição de probabilidade

A partir dos artigos selecionados, foram extraídas informações substanciais para evidenciar os aspectos analisados neste estudo (Quadro 1).
Conforme constatado, o microfone foi o instrumento de captação dos sinais de ausculta cervical mais utilizado, seguido pela sua combinação com o acelerômetro. Já, para análise 
acústica desses sinais, uma variedade de recursos disponíveis, como softwares e/ou algoritmos, foram selecionados de acordo com o objetivo de cada estudo.

\section{DISCUSSÃO}

\section{Instrumentos de captação dos sinais de ausculta cervical}

A ausculta cervical com estetoscópio é uma das técnicas instrumentais não invasivas mais utilizadas pelos fonoaudiólogos para avaliação da fase faríngea da deglutição. Devido à interpretação subjetiva dessa técnica, métodos de ausculta cervical digital com diferentes instrumentos de captação que possibilitam uma análise objetiva e/ou automática dos sinais são apresentados na literatura ${ }^{(21)}$. Entretanto, para que uma nova técnica obtenha aceitabilidade clínica, deve atender critérios, como ser bem pesquisada, de modo que forneça informações sobre sua confiabilidade; ser facilmente aplicada na situação clínica e apresentar, preferencialmente, baixo custo. Ainda, o equipamento utilizado e sua aplicação devem ser padronizados, de maneira que as informações sejam comparáveis entre as clínicas de disfagia ${ }^{(50)}$.

Observou-se, nos estudos selecionados, que os principais instrumentos utilizados para captação dos sinais da deglutição foram o microfone e sua combinação com o acelerômetro, técnica definida como ausculta cervical de alta resolução, que registra sons e vibrações da função deglutitória. Assim como esses métodos, outros instrumentos de registro dos sinais de ausculta cervical também apresentaram importantes resultados nessa área. Essas informações serão descritas a seguir, organizadas de acordo com as principais contribuições que oferecem para prática clínica fonoaudiológica.

As fontes cinemáticas dos sinais acústicos da deglutição ainda não foram totalmente elucidadas, apesar de todas as possibilidades que envolvem a ausculta cervical digital ${ }^{(44)} \mathrm{e}$ a importância que essa interpretação possui. Em vista disso, algumas pesquisas baseadas em diferentes metodologias tiveram essa temática como objeto de estudo.

O perfil espectrográfico da fase faríngea da deglutição normal, para as consistências líquida e purê, em indivíduos saudáveis, maiores de 18 anos, foi estruturado por meio de sinais de ausculta cervical obtidos com um estetoscópio eletrônico ${ }^{(24)}$. O tempo total da fase faríngea foi inferior a 1 segundo e representou quatro eventos da deglutição que podem ser analisados a partir dos tempos obtidos na análise digital da onda acústica:

- o tempo de trânsito faríngeo, que apresentou média de 0,409 segundos e, para análise de deglutições normais, deverá durar, aproximadamente, metade do tempo de apneia da deglutição e estar posicionado no centro do gráfico no estudo da espectrografia;

- o tempo de apneia da deglutição, que apresentou média de 0,78 segundos e fatores acústicos de baixa intensidade, devendo estar no início (ativação de proteção da laringe) e no final (abertura da região glótica) da representação espectrográfica e, por isso, sua posição no gráfico será maior;
- relação temporal entre a ativação dos mecanismos de proteção das vias aéreas inferiores e o início da passagem do bolo alimentar pela fase faríngea, que apresentou média de 0,134 segundos e será representada no início do gráfico da espectrografia, logo após a ativação de proteção laríngea;

- o tempo que a laringe levou para retornar a sua função respiratória após a passagem completa do alimento, que apresentou um intervalo aproximado de 0,20 a 0,26 segundos e sua posição no gráfico será no final.

Um estudo que utilizou sinais de ausculta cervical captados por um microfone condensador e imagens do exame de videofluoroscopia apresentou a divisão do som da deglutição em três períodos, associados a cada fase de seus movimentos: fase oral, que compreende o movimento posterior da língua e do osso hioide; fase faríngea, associada ao movimento laríngeo, elevação do osso hioide, fechamento da epiglote e passagem do bolo para o esôfago; fase de reposicionamento do osso hioide e da laringe, com a reabertura da epiglote ${ }^{(33)}$.

Outro estudo analisou a associação entre os sinais da ausculta cervical de alta resolução, registrados por um microfone de contato e um acelerômetro triaxial, e os eventos cinemáticos da deglutição durante a fase faríngea, avaliados por imagens do exame de videofluoroscopia. Características de domínio do tempo e frequência foram calculadas e os valores máximos de cada variável, como desvio padrão, assimetria, curtose, frequência centroide, largura de banda e entropia de onda, foram associados à elevação do hioide, fechamento do vestíbulo laríngeo, abertura do esfíncter esofágico superior, contato da base da língua e parede posterior da faringe ${ }^{(44)}$. Além disso, outros pesquisadores evidenciaram que os movimentos horizontais e verticais da parte anterior e posterior do osso hioide também apresentam relação com os sons e vibrações da deglutição ${ }^{(43)}$.

$\mathrm{Na}$ investigação de deglutições normais e alteradas em crianças, os sinais de ausculta cervical foram obtidos por um microfone condensador de eletreto e comparados ao exame de videofluoroscopia. Um primeiro estudo destacou sinais acústicos e perceptuais, indicativos de aspiração na presença de respiração ruidosa e de um ou mais dos seguintes sons após a deglutição: tosse, chiado, estertores, pigarro e estridor. Os profissionais de saúde foram encorajados a encaminhar o paciente para uma avaliação instrumental adicional, quando da presença desses sinais na ausculta. Os autores descrevem como padrão indicativo de normalidade a presença de um som de liberação glótica junto a sons respiratórios normais após a deglutição ${ }^{(25)}$. Outro estudo apresentou a possibilidade de identificar aspiração por meio da curva de densidade espectral, que é um parâmetro capaz de verificar alterações nos sinais sonoros respiratórios imediatamente após a deglutição. A curva de deglutições com aspiração apresentou um padrão ascendente, enquanto a curva de deglutições normais foi plana ${ }^{(37)}$.

Em estudo desenvolvido com sinais de ausculta cervical de alta resolução, os autores observaram que, para diferenciar deglutições normais das alteradas, uma série de recursos estatísticos devem ser empregados na análise das características do sinal acústico $^{(42)}$. Quando as características do sinal de ausculta cervical 
de alta resolução foram combinadas a métodos estatísticos e a técnicas de aprendizado de máquina, puderam prever se as deglutições eram de pessoas saudáveis ou de pacientes com doenças neurodegenerativas e suspeita de disfagia, com alto grau de precisão (99\%), sensibilidade (100\%) e especificidade $(99 \%)^{(46)}$.

Por fim, ao utilizar um sensor piezoelétrico para registro dos sons da deglutição e imagens do exame de videofluoroscopia, um estudo destacou que o tempo de retardo de elevação e o tempo de elevação laríngea foram significativamente prolongados em pacientes com disfagia, principalmente em alimentos com maior viscosidade. Além disso, a taxa de ocorrência do padrão inspiração-deglutição aumentou significativamente no grupo desses pacientes ${ }^{(27)}$

Quando analisadas as variações dos resultados obtidos em relação às características do alimento ingerido, pôde-se verificar, nos estudos, que a laringe desempenha movimentos complexos para deglutições de bolos alimentares de maior viscosidade $^{(38)}$; o uso combinado de sensor de emissão acústica e gráficos de distribuição de probabilidade (gráficos Q-Q) permite distinguir diferenças de viscosidades ${ }^{(26)}$; as medidas de amplitude de pico e a energia diminuem significativamente com a viscosidade do bolo alimentar, o intervalo de tempo, pico a pico, e a duração aumentam com o volume do bolo ${ }^{(49)}$; o padrão acústico da deglutição se modifica em relação à consistência e volume do bolo alimentar com o passar dos anos, sendo que, nos idosos, apresenta uma curva com menor amplitude e maior tempo do que nos adultos ${ }^{(13)}$.

Para análise quanto às características do alimento, foram utilizados os seguintes instrumentos: microfone condensador de eletreto bidirecional ${ }^{(38)}$; microfone condensador de garganta e sensor de emissão acústica ${ }^{(26)}$; sensor Doppler e microfone condensador de eletreto omnidirecional ${ }^{(49)}$; sensor Doppler ${ }^{(13)}$. Observou-se uma grande diversidade metodológica nos estudos analisados. Embora outros dispositivos, como estetoscópio eletrônico, sensor de emissão acústica, sensor Doppler e sensor piezoelétrico também tenham evidenciado resultados importantes para clínica, o microfone e sua combinação com o acelerômetro se destacaram. Entretanto, mesmo na seleção desses dois instrumentos existe uma variedade de modelos disponíveis para cada um, que possibilitam diferentes registros do sinal.

Apesar dos sinais acústicos obtidos com o microfone e o acelerômetro possuírem as mesmas fontes fisiológicas, diferenças nos domínios do tempo e da frequência são observadas, demonstrando que os dados fornecidos por esses instrumentos não são intercambiáveis ${ }^{(41)}$. Tanto os sons, quanto as vibrações da deglutição apresentam informações úteis sobre a função. Em vista disso, o uso combinado do microfone e do acelerômetro para obtenção dos sinais de ausculta cervical pode ser promissor para os pesquisadores da área. Eles acreditam que o sistema de ausculta cervical de alta resolução pode ser um valioso contribuinte para o rastreamento da disfagia e, no futuro, um método não invasivo e adjuvante no diagnóstico de distúrbios de deglutição ${ }^{(45)}$.

Com base nos estudos analisados, destaca-se que a seleção do instrumento de captação dos sinais de ausculta cervical digital mais adequado é uma etapa imprescindível a ser padronizada para utilização dessa técnica na prática clínica fonoaudiológica. Entretanto, para que esses sinais forneçam informações substanciais para avaliação da deglutição, a metodologia de análise deve ser criteriosamente selecionada. Diante disso, vale considerar que uma análise mediante parâmetros objetivos também depende de conhecimento prévio do examinador para interpretá-los e que a maior contribuição seria se essa análise pudesse ser feita de maneira automática.

\section{Métodos de análise acústica}

A análise acústica dos sinais de ausculta cervical pode ser realizada com uma variedade de recursos disponíveis. Nos estudos incluídos nesta pesquisa foram identificados softwares, sendo LabView, Matlab, Adobe Audition, VoxMetria e Audacity os mais utilizados, além de algoritmos selecionados e de aprendizado de máquina, algoritmos e programa de processamento de sinal desenvolvidos pelos autores, aplicativo de smartphone e gerador de funções. A seleção do melhor método é guiada pelo objetivo de cada estudo, ou seja, pelas características que se deseja extrair e analisar. Além disso, a possibilidade de criar novos métodos de análise vem motivando alguns pesquisadores não apenas da área da saúde, mas também da engenharia e informática.

Entre os métodos de análise, um estudo desenvolveu e avaliou três algoritmos para detectar distúrbio e três para detectar eficiência da deglutição ${ }^{(23)}$. Outros pesquisadores buscaram monitorar a ingestão alimentar diária por meio de um aplicativo de smartphone, desenvolvido e programado com algoritmos específicos, para reconhecer e classificar diferentes alimentos ${ }^{(32)}$. Já em um terceiro estudo, um programa de processamento de sinal foi criado para monitorar e avaliar a deglutição de maneira quantitativa ${ }^{(49)}$. Os resultados dessas pesquisas caracterizaram tais métodos de análise desenvolvidos com potencial para triagem e monitoramento da deglutição mediante novas pesquisas.

Quando combinados o uso de recursos estatísticos à análise acústica dos sinais de ausculta cervical, muitos parâmetros podem ser obtidos. Entretanto, nenhum recurso estatístico único é capaz de diferenciar deglutições seguras das inseguras ${ }^{(40)}$. De acordo com isso, pesquisadores realizaram novo estudo, utilizando uma ampla seleção de parâmetros estatísticos para caracterizar as deglutições saudáveis e as com distúrbio. Observaram que deglutições normais de grupo controle saudável e de pacientes com disfagia têm padrões distintos, apesar da ausência de aspiração ${ }^{(42)}$.

A fim de colaborar com os métodos de análise, os algoritmos de aprendizado de máquina, definidos como um processo iterativo para determinar a acurácia a partir de um padrão-ouro, apresentaram resultados importantes na área de pesquisa discutida. Esse recurso é citado na literatura como útil para detecção, reconhecimento e classificação dos eventos da deglutição. Quando aplicado em um estudo, o método apresentou acurácia global de 97,7\% para detecção de eventos acústicos e $91,7 \%$ para sons de deglutição por fechamento glótico, na presença de outras fontes de ruído (pronúncia de um fonema e som de pigarro) $)^{(21)}$. Em outro estudo, produziu resultados com taxas máximas de reconhecimento de 78,4\% para deglutição ${ }^{(28)}$.

O uso de aprendizado de máquina de recursos de sinal de ausculta cervical de alta resolução demonstrou viabilidade de rastreamento preciso e automatizado do 
deslocamento do osso hioide, sem o uso de exame de videofluorosocopia da deglutição, com nível de precisão de 50,75\%. Embora esse nível não pareça significativo, a estrutura do osso hioide é muito pequena e, em vista disso, a possibilidade de detectar sua posição em mais de $50 \%$ dos segmentos de deglutição sem o uso de imagens foi considerada bastante notável ${ }^{(45)}$.

Conforme constatado, os algoritmos de aprendizado de máquina demonstraram ser um recurso promissor para análise dos sinais de ausculta cervical na prática clínica fonoaudiológica, por meio de evidências de sua alta acurácia. Com isso, possibilitaram a utilização de métodos não invasivos de captação e análise automática para triagem, avaliação e monitoramento da deglutição. Entretanto, novas pesquisas são necessárias para padronização e validação desses algoritmos quanto ao método de captação dos sinais de ausculta cervical utilizado e quanto a variáveis, como deglutição normal e alterada por condições médicas distintas, aspiração silente, idade, sexo, índice de massa corporal, volume e consistência dos alimentos.

De modo geral, diferentes métodos de captação e análise dos sinais de ausculta cervical foram apresentados e descritos quanto ao potencial para implementação na prática clínica. Esses métodos evidenciaram os avanços das pesquisas em parceria entre as áreas da saúde, engenharia e informática, em busca de recursos que possibilitam registro e análise objetiva e/ou automática dos sinais da deglutição, com boa acurácia e fácil aplicabilidade clínica. Além disso, os estudos apresentados permitem aos fonoaudiólogos uma reflexão sobre a utilização de recursos tecnológicos na clínica e seu potencial para aprimoramento da avaliação clínica das disfagias orofaríngeas.

\section{CONCLUSÃO}

Esta revisão revelou um cenário de pesquisa atual e em potente crescimento sobre ausculta cervical e análise dos sinais da deglutição.

O método de ausculta cervical de alta resolução, combinado aos algoritmos de aprendizado de máquina, demonstrou grandes potenciais para utilização na prática clínica fonoaudiológica para avaliação e monitoramento da deglutição. Novos estudos devem ser realizados, a fim de padronizar e validar esses métodos.

\section{REFERÊNCIAS}

1. Dray TG, Hillel AD, Miller RM. Dysphagia caused by neurologic deficits. Otolaryngol Clin North Am. 1998 Jun;31(3):507-24. http:// dx.doi.org/10.1016/S0030-6665(05)70067-0. PMid:9628947.

2. Macedo ED Fo, Gomes GF, Furkim AM. Manual de cuidados do paciente com disfagia. São Paulo: Lovise; 2000. 122 p.

3. Marchesan IQ. O que se considera normal na deglutição. In: Jacobi, JS, Levy DS, Silva LMC, organizadores. Disfagia: avaliação e tratamento. Rio de Janeiro: Revinter; 2003. p. 3-17.

4. Cámpora H, Falduti A. Evaluación y tratamiento de las alteraciones de la deglución. Rev Am Med Respir. [Internet]. 2012 [citado em
2020 Nov 15];12(3):98-107. Disponível em: http://www.redalyc.org/ articulo.oa? $\mathrm{id}=382138394004$

5. Ferrucci JL, Mangilli LD, Sassi FC, Limongi SCO, Andrade CRF. Sons da deglutição na prática fonoaudiológica: análise crítica da literatura. Einstein. 2013;11(4):535-9. http://dx.doi.org/10.1590/ S1679-45082013000400024. PMid:24488399.

6. Padovani AR, Moraes DP, Mangili LD, Andrade CRF. Protocolo fonoaudiológico de avaliação do risco para disfagia (PARD). Rev Soc Bras Fonoaudiol. 2007;12(3):199-205. http://dx.doi.org/10.1590/ S1516-80342007000300007.

7. Patatas $\mathrm{OHG}$, Gonçalves MIR, Chiari BM, Gielow I. Parâmetros de duração dos sinais acústicos da deglutição de indivíduos sem queixa. Rev Soc Bras Fonoaudiol. 2011;16(3):282-90. http://dx.doi.org/10.1590/ S1516-80342011000300008.

8. Hamlet SL, Patterson RL, Fleming SM, Jones LA. Sounds of swallowing following total laryngectomy. Dysphagia. 1992;7(3):160-5. http:// dx.doi.org/10.1007/BF02493450. PMid:1499359.

9. Morinière $\mathrm{S}$, Boiron $\mathrm{M}$, Alison $\mathrm{D}$, Makris $\mathrm{P}$, Beutter $\mathrm{P}$. Origin of the sound components during pharyngeal swallowing in normal subjects. Dysphagia. 2008 Set;23(3):267-73. http://dx.doi.org/10.1007/s00455007-9134-z. PMid:18071792.

10. Spadotto AA, Gatto AR, Cola PC, Montagnoli AN, Schelp AO, Silva RG, et al. Software para análise quantitativa da deglutição. Radiol Bras. 2008;41(1):25-8. http://dx.doi.org/10.1590/S010039842008000100008 .

11. Santini CS. Disfagia neurogênica. In: Furkim AM, Santini CS, organizadores. Disfagias orofaríngeas. São Paulo: Pró Fono; 2001. p. 19-34.

12. Santos RS, Macedo-Filho E. D. Sonar Doppler como instrumento de avaliação da deglutição. Arq Int Otorrinolaringol. 2006;10(3):8291.

13. Soria FS, Silva RG, Furkim AM. Acoustic analysis of oropharyngeal swallowing using Sonar Doppler. Rev Bras Otorrinolaringol. 2016 Jan-Fev;82(1):39-46. http://dx.doi.org/10.1016/j.bjorl.2015.12.001. PMid:26718958.

14. Montoni NPC. Métodos instrumentais complementares. In: Dedivitis RA, Santoro PP, Arakawa-Sugueno L, organizadores. Manual prático de disfagia: diagnóstico e tratamento. Rio de Janeiro: Revinter; 2017.

15. Vale-Prodomo LP, Carrara-de-Angelis E, Barros APB. Avaliação clínica fonoaudiológia das disfagias. In: Jotz GP, Carrara-de-Angelis E, Barros APB, organizadores. Tratado de deglutição e disfagia: no adulto e na criança. Rio de Janeiro: Revinter; 2009. p. 61-7.

16. Castro E, Fonseca L, Matos JP, Bernardo T, Silva AP. Videoendoscopia da deglutição: protocolo de avaliação. Port J ORL. 2012;50(3):197204. http://dx.doi.org/10.34631/sporl.112.

17. Coriolano MGWS, Lins OG, Belo LR, Menezes DC, Moraes SRA, Asano AG, et al. Monitorando a deglutição através da eletromiografia de superfície. Rev CEFAC. 2020;12(3):434-40. http://dx.doi.org/10.1590/ S1516-18462010005000015.

18. Honda T, Baba T, Fujimoto K, Nagao K, Takahashi A, Ichikawa T. Swallowing sound waveform and its clinical significance: evaluation using ultrasonography. J. Oral Health Biosci. 2015;28(1):21-7.

19. Gonçalves MIR, Oliveira IC No. Diagnóstico instrumental na deglutição normal e patológica. In: Fernandes FDM, Mendes BCA, Navas ALPGP, organizadores. Tratado de Fonoaudiologia. 2. ed. São Paulo: Roca; 2009. p. 468-70. 
20. Youmans SR, Stierwalt JA. Normal swallowing acoustics across age, gender, bolus viscosity, and bolus volume. Dysphagia. 2011;26(4):37484. http://dx.doi.org/10.1007/s00455-010-9323-z. PMid:21225287.

21. Sánchez-Cardona Y, Orozco-Duque A, Roldán-Vasco S. Caracterización y clasificación de señales de auscultación cervical adquiridas con estetoscopio para detección automática de sonidos deglutorios. Rev Mex Ing Biomed. 2018;39(2):205-16. http://dx.doi.org/10.17488/ RMIB.39.2.6.

22. Dudik JM, Coyle JL, Sejdić E. Dysphagia screening: contributions of cervical auscultation signals and modern signal-processing techniques. IEEE Trans Hum Mach Syst. 2015;45(4):465-77. http:// dx.doi.org/10.1109/THMS.2015.2408615. PMid:26213659.

23. Steele CM, Mukherjee R, Kortelainen JM, Pölönen H, Jedwab M, Brady SL, et al. Development of a non-invasive device for swallow screening in patients at risk of oropharyngeal dysphagia: results from a prospective exploratory study. Dysphagia. 2019;34(5):698-707. http://dx.doi.org/10.1007/s00455-01809974-5. PMid:30612234.

24. Vargas García M. Perfil espectrográfico de la deglución normal en el adulto. Nutr Hosp. 2019;36(2):412-9. http://dx.doi.org/10.20960/ nh.2173. PMid:30836762.

25. Frakking T, Chang A, O’Grady K, David M, Weir K. Aspirating and nonaspirating swallow sounds in children: a pilot study. Ann Otol Rhinol Laryngol. 2016;125(12):1001-9. http://dx.doi. org/10.1177/0003489416669953. PMid:27683588.

26. Chikai M, Kamiyanagi A, Kimura K, Seki Y, Endo H, Sumita Y, et al. Pilot study on an acoustic measurements system of the swallowing function using an acoustic-emissions microphone. J Adv Comput Intell Intell Informar. 2017;21(2):293-300. http://dx.doi.org/10.20965/ jaciii.2017.p0293.

27. Yagi N, Nagami S, Lin MK, Yabe T, Itoda M, Imai T, et al. A noninvasive swallowing measurement system using a combination of respiratory flow, swallowing sound, and laryngeal motion. Med Biol Eng Comput. 2017;55(6):1001-17. http://dx.doi.org/10.1007/s11517-016-1561-2. PMid:27665103.

28. Lee KS. Food intake detection using ultrasonic doppler sonar. IEEE Sens J. 2017;17(18):6056-68. http://dx.doi.org/10.1109/JSEN.2017.2734688.

29. Cagliari CF, Jurkiewicz AL, Santos RS, Marques JM. Análise por sonar Doppler dos sons da deglutição em indivíduos pediátricos normais. Rev Bras Otorrinolaringol. 2009;75(5):706-15. http://dx.doi.org/10.1590/ S1808-86942009000500016.

30. Mendes KDS, Silveira RCCP, Galvão CM. Revisão integrativa: método de pesquisa para a incorporação de evidências na saúde e na enfermagem. Texto Contexto Enferm. 2008;17(4):758-64. http:// dx.doi.org/10.1590/S0104-07072008000400018.

31. Botelho LLR, Cunha CCA, Macedo M. O método da revisão integrativa nos estudos organizacionais. GeS. 2011;5(11):121-36. http://dx.doi. org/10.21171/ges.v5i11.1220.

32. Bi Y, Lv M, Song C, Xu W, Guan N, Yi W. AutoDietary: a wearable acoustic sensor system for food intake recognition in daily life. IEEE Sens J. 2016;16(3):806-16. http://dx.doi.org/10.1109/ JSEN.2015.2469095.

33. Honda T, Baba T, Fujimoto K, Goto T, Nagao K, Harada M, et al. Characterization of swallowing sound: preliminary investigation of normal subjects. PLoS One. 2016;11(12):e0168187. http://dx.doi. org/10.1371/journal.pone.0168187. PMid:27959902.

34. Kamiyanagi A, Sumita Y, Ino S, Chikai M, Nakane A, Tohara $\mathrm{H}$, et al. Evaluation of swallowing ability using swallowing sounds in maxillectomy patients. J Oral Rehabil. 2018;45(2):126-31. http:// dx.doi.org/10.1111/joor.12593. PMid:29197111.

35. Li Q, Minagi Y, Ono T, Chen Y, Hori K, Fujiwara S, et al. The biomechanical coordination during oropharyngeal swallowing: an evaluation with a non-invasive sensing system. Sci Rep. 2017;7(1):15165. http://dx.doi.org/10.1038/s41598-017-15243-6. PMid:29123186.

36. Frakking TT, Chang AB, O'Grady KF, Yang J, David M, Weir KA. Acoustic and perceptual profiles of swallowing sounds in children: normative data for 4-36 months from a cross-sectional study cohort. Dysphagia. 2017;32(2):261-70. http://dx.doi.org/10.1007/s00455016-9755-1. PMid:27830392.

37. Almeida ST, Ferlin EL, Maciel AC, Fagondes SC, Callegari-Jacques SM, Fornari F, et al. Acoustic signal of silent tracheal aspiration in children with oropharyngeal dysphagia. Logoped Phoniatr Vocol. 2018;43(4):169-74. http://dx.doi.org/10.1080/14015439.2018.1487 993. PMid:30111199.

38. Kurihara T, Kaburagi T, Kumagai S, Matsumoto T. Development of swallowing-movement-sensing device and swallowing-state-estimation system. IEEE Sens J. 2019;19(9):3532-42. http://dx.doi.org/10.1109/ JSEN.2019.2894744.

39. Miyagi S, Sugiyama S, Kozawa K, Moritani S, Sakamoto SI, Sakai O. Classifying dysphagic swallowing sounds with support vector machines. Healthcare . 2020;8(2):103. http://dx.doi.org/10.3390/ healthcare8020103. PMid:32326267.

40. Dudik JM, Kurosu A, Coyle JL, Sejdić E. A statistical analysis of cervical auscultation signals from adults with unsafe airway protection. J Neuroeng Rehabil. 2016;13(1):7. http://dx.doi.org/10.1186/s12984015-0110-9. PMid:26801236.

41. Movahedi F, Kurosu A, Coyle JL, Perera S, Sejdić E. A comparison between swallowing sounds and vibrations in patients with dysphagia. Comput Methods Programs Biomed. 2017;144:179-87. http://dx.doi. org/10.1016/j.cmpb.2017.03.009. PMid:28495001.

42. Dudik JM, Kurosu A, Coyle JL, Sejdić E. Dysphagia and its effects on swallowing sounds and vibrations in adults. Biomed Eng Online. 2018;17(1):69. http://dx.doi.org/10.1186/s12938-018-0501-9. PMid:29855309.

43. Rebrion C, Zhang Z, Khalifa Y, Ramadan M, Kurosu A, Coyle JL, et al. High-resolution cervical auscultation signal features reflect vertical and horizontal displacements of the hyoid bone during swallowing. IEEE J Transl Eng Health Med. 2018;7:1800109. http://dx.doi.org/10.1109/ jtehm.2018.2881468. PMid:30701145.

44. Kurosu A, Coyle JL, Dudik JM, Sejdic E. Detection of swallow kinematic events from acoustic high-resolution cervical auscultation signals in patients with stroke. Arch Phys Med Rehabil. 2019;100(3):501-8. http://dx.doi.org/10.1016/j.apmr.2018.05.038. PMid:30071198.

45. Donohue C, Mao S, Sejdić E, Coyle JL. Tracking hyoid bone displacement during swallowing without videofluoroscopy using machine learning of vibratory signals. Dysphagia. 2021 Abr;36(2):259-69. http://dx.doi.org/10.1007/s00455-020-10124-z. PMid:32419103.

46. Donohue C, Khalifa Y, Perera S, Sejdić E, Coyle JL. A preliminary investigation of whether hrca signals can differentiate between swallows from healthy people and swallows from people with neurodegenerative diseases. Dysphagia. 2021 Ago;36(4):635-43. http://dx.doi.org/10.1007/ s00455-020-10177-0. PMid:32889627.

47. Kamiyanagi A, Sumita Y, Chikai M, Kimura K, Seki Y, Ino S, et al. Evaluation of swallowing sound using a throat microphone with an AE sensor in patients wearing palatal augmentation prosthesis. J 
Adv Comput Intell Intell Informar. 2017;21(3):573-80. http://dx.doi. org/10.20965/jaciii.2017.p0573.

48. Taveira KVM, Santos RS, Leão BLC, Stechman J No, Pernambuco L, Silva LKD, et al. Diagnostic validity of methods for assessment of swallowing sounds: a systematic review. Rev Bras Otorrinolaringol. 2018;84(5):638-52. http://dx.doi.org/10.1016/j.bjorl.2017.12.008. PMid:29456200.
49. Choi Y, Kim M, Lee B, Yang X, Kim J, Kwon D, et al. Development of an ultrasonic doppler sensor-based swallowing monitoring and assessment system. Sensors. 2020;20(16):4529. http://dx.doi.org/10.3390/ s20164529. PMid:32823533.

50. Cichero JA, Murdoch BE. Detection of swallowing sounds: methodology revisited. Dysphagia. 2002;17(1):40-9. http://dx.doi.org/10.1007/ s00455-001-0100-x. PMid:11824392. 
Apêndice A. Estratégia de busca nas bases de dados

Scopus (TITLE-ABS-KEY (deglutition) OR TITLE-ABS-KEY (deglutitions) OR TITLE-ABS-KEY (swallowing) OR TITLE-ABS-KEY (swallowings) OR TITLE-ABS-KEY (swallow) OR TITLE-ABS-KEY (swallows) AND TITLE-ABS-KEY ("acoustic analysis") OR TITLE-ABS-KEY ("acoustical analysis") OR TITLE-ABS-KEY (auscultation) OR TITLE-ABS-KEY ("cervical auscultation") OR TITLE-ABS-KEY ("swallowing sounds") OR TITLE-ABS-KEY ("swallow sounds") OR TITLE-ABS-KEY ("signal processing")

OR TITLE-ABS-KEY (acoustics) OR TITLE-ABS-KEY (acoustic) OR TITLE-ABS-KEY (software) AND TITLE-ABS-KEY (accelerometry) OR TITLE-ABS-KEY ("swallowing accelerometry signals") OR TITLE-ABS-KEY (stethoscope) OR TITLE-ABSKEY ("digital stethoscope") OR TITLE-ABS-KEY ("electronic stethoscope") OR TITLE-ABS-KEY ("doppler effect") OR TITLEABS-KEY ("sonar doppler") OR TITLE-ABS-KEY (microphone))

MEDLINE/ (("deglutition"[Title/Abstract] OR "deglutitions"[Title/Abstract] OR "swallowing"[Title/Abstract] OR "swallowings"[Title/Abstract] OR Pubmed "swallow"[Title/Abstract] OR "swallows"[Title/Abstract]) AND ("acoustic analysis"[Title/Abstract] OR "acoustical analysis"[Title/ Abstract] OR "auscultation"[Title/Abstract] OR "cervical auscultation"[Title/Abstract] OR "swallowing sounds"[Title/Abstract] OR "swallow sounds"[Title/Abstract] OR "signal processing"[Title/Abstract] OR "acoustics"[Title/Abstract] OR "acoustic"[Title/

Abstract] OR "software"[Title/Abstract])) AND ("accelerometry"[Title/Abstract] OR "swallowing accelerometry signals"[Title/ Abstract] OR "stethoscope"[Title/Abstract] OR "digital stethoscope"[Title/Abstract] OR "electronic stethoscope"[Title/Abstract] OR "doppler effect"[Title/Abstract] OR "sonar doppler"[Title/Abstract] OR "microphone"[Title/Abstract])

Web of TS=(deglutition OR deglutitions OR swallowing OR swallowings OR swallow OR swallows) AND TS=(acoustic analysis OR $\begin{array}{ll}\text { Science } & \text { acoustical analysis OR auscultation OR cervical auscultation OR swallowing sounds OR swallow sounds OR signal processing } \\ & \text { OR acoustics OR acoustic OR software) AND TS=(accelerometry OR swallowing accelerometry signals OR stethoscope OR }\end{array}$ digital stethoscope OR electronic stethoscope OR doppler effect OR sonar doppler OR microphone) 